\title{
Acoustic feature analysis in the perception of voicing contrasts
}

\author{
RANDY L. DIEHL and DEBORAH M. ROSENBERG \\ University of Texas at Austin, Austin, Texas 78712
}

\begin{abstract}
Various types of acoustic cues have been shown to signal voicing contrasts in initial prestressed stop consonants. Two of the most important of these cues are the time interval between the release burst and the onset of voicing (voice onset time) and the duration of voiced transitions. In the present experiment, a selective adaptation procedure was used to investigate possible feature extraction mechanisms which underlie the perception of voicing. Subjects first identified either of two series of test stimuli, [ba-pha] or [ga-k $\left.\mathbf{h}_{\mathbf{a}}\right]$. Next they listened to repeated presentations of an adapting stimulus and then again identified the original test series. Adapting stimuli having the same value of voice onset time but different voiced transition durations produced differential (and sometimes opposite) effects on the identification of the test stimuli. In every case, the adapting stimulus with the greater duration of voiced transitions led to larger reduction in voiced responses or to a smaller increase in voiceless responses. These results are incompatible with models of voicing perception based strictly on detectors for voice onset time. The results also suggest that the adaptation effect occurs at a point in the system prior to the actual phonetic decision.
\end{abstract}

Much research has been aimed at discovering the articulatory and acoustical basis for the voicedvoiceless distinction in initial prestressed consonants. In a spectrographic study of naturally produced words, Lisker \& Abramson (1964) found that an important correlate of phonemic distinctions along the voicing dimension is variation in voice onset time (VOT), the interval between the release burst and the onset of periodicity that reflects glottal pulsing. Experiments with synthetic speech (Abramson \& Lisker, 1970, 1973; Lisker \& Abramson, 1970) appeared to confirm the role of VOT as a perceptual cue for voicing distinctions. Stimuli with small VOT values were perceived by English speakers as voiced ([b d g]), whereas stimuli with greater VOT values (over $\mathbf{4 0} \mathrm{msec}$ ) were perceived as voiceless ([ph $\left.\mathrm{th}^{\mathrm{h}} \mathrm{k}^{\mathrm{h}}\right]$ ).

In the series of synthetic test syllables used by Lisker and Abramson, increases in VOT over a certain critical range were accompanied by decreases in the duration of voiced format transitions. It is conceivable, therefore, that the operative cue for the voiced-voiceless distinction is not VOT per se but rather the presence or absence of significant formant transitions following voicing onset. To test this hypothesis, Stevens and Klatt (1974) constructed a stimulus set in which VOT and voiced transition duration (VTD) varied orthogonally. When subjects identified these stimuli, the VOT value of the voicedvoiceless boundary was found to vary as a function

This research was supported by a Biomedical Sciences Research Grant from the University of Texas at Austin. Requests for reprints should be sent to Randy L. Diehl, Department of Psychology, 330 Mezes, University of Texas, Austin, Texas 78712. of VTD, thus indicating the perceptual significance of the latter cue. The role of voiced transitions (particularly the first-formant transition) in the perception of voicing contrasts was also demonstrated in studies by Summerfield and Haggard (1974, Note 1). It should be noted, however, that in none of these experiments was VOT actually ruled out as a voicing cue. To the contrary, Stevens and Klatt (1974) found that the VTD corresponding to the voiced-voiceless boundary tended to increase as VOT increased, and Summerfield and Haggard (1974) showed that VOT is an especially important voicing cue for stimuli lacking first-formant transitions. A recent study by Lisker et al. (Note 2) replicated the results of Stevens and Klatt (1974), underscoring further the fact that neither VOT nor VTD is alone sufficient to account for the perception of voicing contrasts.

In view of the above findings, it is appropriate to reconsider the problem of how the auditory system extracts voicing information from the speech signal. In particular, what is the nature of the feature detection mechanisms which underlie the perception of the voiced-voiceless distinction in initial stops? Cooper (1974) performed a selective adaptation experiment designed to address this question. The selective adaptation paradigm rests on the assumption that repeated presentation of a stimulus having a given set of features will reduce the sensitivity of neural detector mechanisms which normally respond to those features. Thus, perception should be distorted in a predictable manner following adaptation (Eimas, Cooper, \& Corbit, 1973; Eimas \& Corbit, 1973). Cooper first had subjects identify a series of synthetic syllables which varied in VOT (as 
well as VTD through part of the stimulus range). These syllables were perceived as either [ba] or [ $p^{\mathrm{h}} \mathrm{a}$ ]. After this initial identification test, the subjects listened to the repeated presentation of either of two different adapting stimuli and then again identified the original test series. Both of the adapting stimuli had the same value of VOT, but one had a VTD of $10 \mathrm{msec}$ ([da]-short) while the other had a VTD of $40 \mathrm{msec}$ ([da]-long). Interestingly, these two adapting stimuli produced differential effects on the identification of the test series. The [da]-long stimulus caused the boundary between the perceived voiced and voiceless stops to shift significantly toward the voiced end of the test series. On the other hand, the [da]-short stimulus produced a nonsignificant shift of the phonetic boundary toward the voiceless end.

Cooper noted that these results could obviously not be explained by the adaptation of detectors sensitive only to VOT information. He also argued that an account based solely on the adaptation of VTD detectors is inadequate, since the two adapting stimuli produced differential effects even on the identification of stimuli entirely lacking voiced transitions. Instead, Cooper favored the notion of an integrative analyzer which either responds to different voicing cues disjunctively or else responds to some weighted combination of voicing cues.

The present experiment was intended to replicate and extend the findings of Cooper (1974). One potential difficulty in interpreting Cooper's results arises from the fact that the synthetic test stimuli which he used had formant transitions of only $20 \mathrm{msec}$ duration, less than half the average for naturally produced initial bilabial stops (Lehiste \& Peterson, 1961). It is possible that subjects adopted an unusual perceptual strategy in identifying these somewhat abnormal stimuli. If this were indeed the case, then the generality of Cooper's findings may be questioned. We therefore decided to use test stimuli having transition durations more nearly approximating those of natural utterances. Our primary question was whether adaptation with two stimuli having the same VOT value but different values of VTD would produce differential effects on the perception of the voiced-voiceless dimension.

\section{METHOD}

\section{Subjects}

Thirty-three introductory psychology students at the University of Texas at Austin served as subjects. They received course credit for their participation. All were native speakers of English and reported having normai hearing.

\section{Stimuli}

Two series of eight synthetic stop-vowel syllables, varying in both VOT and VTD, were used as test stimuli. In one series, the direction and extent of the first- and second-formant transitions of each stimulus were appropriate for an initial bilabial stop ([b] or $\left.\left[\mathrm{p}^{\mathrm{h}}\right]\right)$; in the other, the transitions were appropriate for an initial velar stop ([g] or $\left.\left[\mathrm{k}^{\mathrm{h}}\right]\right)$. The following vowel in each case was [a]. The parameter values of the stimuli were the same as those used by Lisker and Abramson (1970). ${ }^{1}$

Each series ranged in VOT from 0 to $+70 \mathrm{msec}$ in steps of $10 \mathrm{msec}$. The total transition duration for each stimulus was $50 \mathrm{msec}$ for the bilabial series and $70 \mathrm{msec}$ for the velar series. Thus, increased VOT resulted in decreased VTD across most of the range of the bilabial series and across the entire range of the velar series.

Lisker and Abramson (1970) found that English speakers who identify these stimuli generally place the phonetic boundary at about $22 \mathrm{msec}$ VOT for the bilabial series and at about $42 \mathrm{msec}$ VOT for the velar series. For each of these boundary values, the corresponding VTD is roughly $28 \mathrm{msec}$. For these particular stimuli, therefore, the phonetic boundary appears to be invariantly specified by VTD, not VOT.

Two pairs of adapting stimuli were selected. Each pair consisted of a bilabial and a velar adapting stimulus having the same VOT, but different values of VTD. One such pair had VOT values of $30 \mathrm{msec}$, and the other of $35 \mathrm{msec}$. The VTD values for the $30-\mathrm{msec}$ VOT pair were $20 \mathrm{msec}$ for the bilabial stimulus and $40 \mathrm{msec}$ for the velar stimulus. The corresponding VTD values for the $35-\mathrm{msec}$ VOT pair were $15 \mathrm{msec}$ and $35 \mathrm{msec}$. Apart from VOT and VTD, these adapting stimuli had exactly the same parameter values as either the bilabial or velar test stimuli. Notice that, given the above-mentioned phonetic boundary values obtained by Lisker and Abramson (1970), the bilabial adapting stimulus of each pair should be perceived as voiceless (i.e., [ $p^{\text {ha }}$ ]), whereas the velar stimulus should be perceived as voiced (i.e., [ga]). Hereafter each adapting stimulus will be referred to by subscripting the VOT value after the phonetic representations of the stimulus (e.g., $\left[\mathrm{p}^{\mathrm{h}} \mathrm{a}\right]_{30}$ ). Figure 1 displays spectrograms of two of the adapting stimuli, $\left[\mathrm{p}^{\mathrm{h}} \mathrm{a}\right]_{30}$ and $[\mathrm{ga}]_{30}$.

\section{Procedure}

In every experimental session, subjects first identified one of the two test series. The tape contained 10 instances of each of the eight stimuli, with all items completely randomized. The interval separating the items was $2 \mathrm{sec}$, with an additional 2-sec delay after every eighth item. The subjects were instructed to label each stimulus as " $B$ " or " $P$ "' (" $G$ " or " $K$ ") on an answer sheet provided.

A second identification test was given after selective adaptation. An adapting stimulus was presented repeatedly for periods of $1 \mathrm{~min}$, and after each such period, subjects identified a block of eight stimuli from the same test tape as presented earlier. This continued until all 80 items on the tape were identified. A .5-sec interval separated each presentation of the adapting stimulus

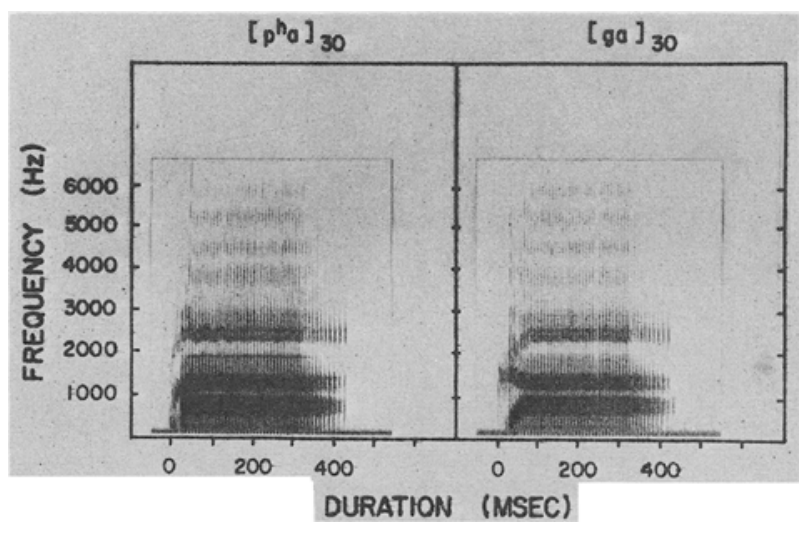

Figure 1. Wide-band spectrograms of two of the adapting stimuli. The $\left[\mathrm{p}^{\mathrm{h}} \mathrm{a}\right]_{30}$ has 20 msec of voiced transitions; the [ga $]_{30}$ has 40 msec of voiced transitions. Both stimuli have a VOT value of $30 \mathrm{msec}$. 
(offset to onset), and there was roughly a $3-\mathrm{sec}$ interval between the end of an adaptation period and the beginning of an initial test stimulus. The subjects were not informed beforehand what the adapting stimulus would be.

At least $24 \mathrm{~h}$ elapsed between experimental sessions. A total of eight conditions were run (4 adapting stimuli $\times 2$ test series). Of the 33 subjects, 12 served in two of these conditions (velar test series: bilabial and velar adaptors with 30 -msec VOT), 11 served in two other conditions (bilabial test series: bilabial and velar adaptors with $30-\mathrm{msec}$ VOT), and 10 served in the remaining four conditions (bilabial and velar test series: bilabial and velar adaptors with 35-msec VOT).

The test tape and the adaptation tape were presented on separate Magnecord 728 tape recorders. Both sets of stimuli were channeled through a Dynaco ST-80 power amplifier and heard binaurally over Koss K6 earphones at a comfortable listening level.

\section{RESULTS}

The data were analyzed in terms of the net increase or decrease in the number of voiced responses following selective adaptation. Let us first consider the cases in which an adaptor of $30 \mathrm{msec} V O T$ was used. The bilabial and velar adaptors had significantly different effects on responses to both the bilabial test series $(p<.02)^{2}$ and the velar test series $(p<.01)$. With respect to the bilabial series, the bilabial adaptor $\left(\left[p^{\mathrm{h}} \mathrm{a}\right]_{30}\right)$ increased the number of voiced responses relative to preadaptation performance $(\mathrm{p}<.05)$, while the velar adaptor $\left([\mathrm{ga}]_{30}\right)$ reduced the number of voiced responses $(p<.05)$. For the velar series, the pattern was somewhat different. Both the $\left[\mathrm{ph}^{\mathrm{h}} \mathrm{a}\right]_{30}$ adaptor and the $[\mathrm{ga}]_{30}$ adaptor decreased the number of voiced responses $(p<.05$ and $p<.001$, respectively), but the latter stimulus produced a reliably greater decrement than the former as noted.

Next we consider the effects of adapting with $\left[\mathrm{p}^{\mathrm{h}} \mathrm{a}\right]_{35}$ and $[\mathrm{ga}]_{35}$. Again, despite having the same VOT value, these two stimuli produced different effects on the identification of both the bilabial series $(p<.01)$ and the velar series $(p<.05)$. The $\left[p^{h} a\right]_{35}$ adaptor increased the number of voiced responses to the bilabial test series $(p<.01)$, but $[\mathrm{ga}]_{35}$ had no significant effect on the identification of the series. Finally, with respect to the velar test series, adapting with $\left[\mathrm{ph}^{\mathrm{h}} \mathrm{]_{35 }}\right.$ led to an increase in voiced responses $(p<.05)$, whereas $[\mathrm{ga}]_{35}$ produced a decrease $(\mathrm{p}<.05)$. Figure 2 shows group identification functions, before and after selective adaptation, for each of the eight conditions described.

\section{DISCUSSION}

The present results flatly disconfirm any model of voicing perception based solely on detectors of absolute VOT information. In every case that we tested, adaptors having identical VOT values but different durations of voiced transitions produced differential effects on the identification of a voiced-voiceless stimulus series. These results are thus in full accord with those of Cooper (1974), despite rather considerable differences between the test stimulus parameters used in the two experiments.

The variable of VTD would appear to be responsible for differential adaptation effects produced by two stimuli having the same VOT. For every such stimulus pair, the member with the greater VTD value led to a larger reduction in voiced responses or to a smaller increase in voiceless responses than did the member with the smaller VTD value. Indeed, for two of the stimulus pairs, the adaptation effects

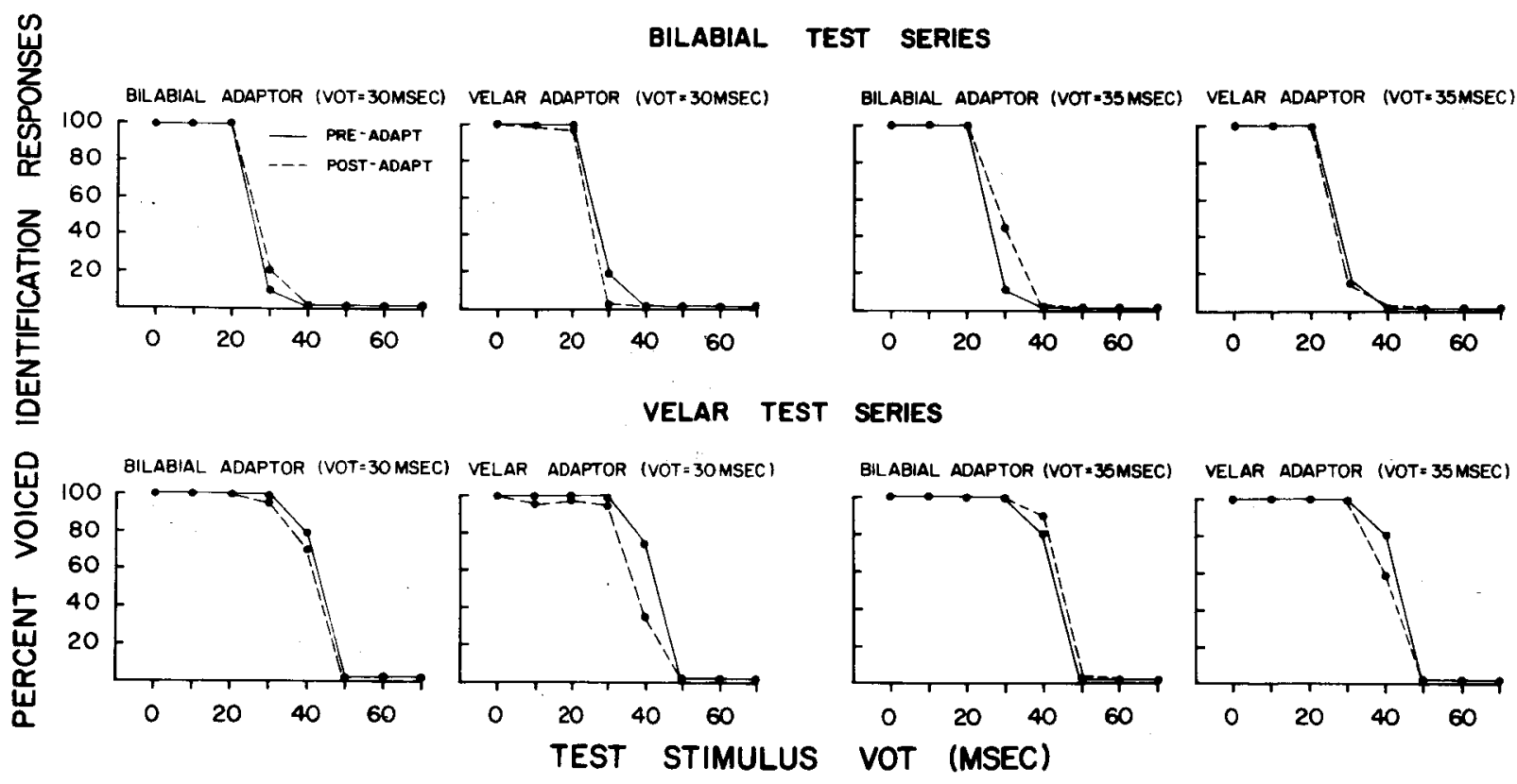

Figure 2. Group identification functions for each of the eight adaptation conditions. 
produced by each member were in opposite directions. This lends additional support to the claim of Stevens and Klatt (1974) that VTD has a critical role in the perception of voicing contrasts.

The present results unfortunately do not speak to the issue of whether adaptation occurs at a cuespecific or an integrative level of analysis. Cooper (1974) tentatively ruled out a cue-specific interpretation of his data on the grounds that adaptors with different VTD values had produced different effects on the identification of test stimuli entirely lacking voiced formant transitions. He correctly noted, however, that this argument rests on an unproved assumption, viz., that the detector for long VTD values does not respond when no voiced transitions are present. The test stimuli used in the present experiment had much longer formant transitions (and hence longer VTD values) than those used by Cooper, and therefore it is quite possible that the adaptation effects we obtained occurred at the site of extraction of VTD information. On the other hand, an interpretation based on an integrative level of analysis obviously cannot be discounted. ${ }^{3}$

One special type of integrative hypothesis would hold that adaptation takes place primarily at or beyond that point in the system where ultimate phonetic decisions are made. On this view, the direction and magnitude of the present adaptation effects would have depended on whether the adapting stimulus is perceived as voiced or voiceless and not on particular acoustic properties of the stimulus such as VOT or VTD. This hypothesis is compatible with most of the present findings. In general, an adaptor perceived as voiced reduced the test stimuli identified as voiced, whereas just the opposite occurred if the adaptor was perceived as voiceless. However, there was one important exception to this generalization. For the velar test series, $\left[\mathrm{p}^{\mathrm{h}} \mathrm{a}\right]_{30}$ actually reduced the number of voiced responses. It can be seen from Figure 2 that this stimulus, when it appeared in the test series, was identified as voiceless between $80 \%$ and $90 \%$ of the time. Thus the direction of the adaptation effect produced by $\left[p^{\mathrm{ha}}\right]_{30}$ in this case appears to be incompatible with the strong phonetic hypothesis under consideration. This result is consistent with'a recent finding of Blumstein and Stevens (Note 3 ), who adapted subjects with a stimulus containing conflicting placeof-articulation cues. Though the subjects identified the stimulus as having a particular place value, it produced an adaptation effect in the direction opposite to that expected on the basis of phonetic labeling. It should be noted, however, that several other experiments (Diehl, 1975; Diehl \& Groves, Note 4) have suggested that under certain conditions the boundary shift is determined more by the perceived phonetic quality of adapting stimulus than by its acoustic properties. Some possible reasons for these apparently discrepant results will be explored in detail in a forthcoming paper (Diehl \& Groves, Note 4).

If adaptation is indeed occurring at an integrative level of voicing analysis, as argued by Cooper, then the present results suggest that it is a level which precedes the ultimate phonetic decision. Some recent models of voicing perception (Ades, Note 5; Summerfield, Note 6) provide for a number of intermediate processing stages, e.g., rate normalization and cue reweighting, between the initial extraction of acoustic properties and the phonetic decision. Selective adaptation may conceivably affect any and all such intermediate processing stages in addition to the acoustic property detectors themselves. Future research must attempt to isolate and explore each of these possibilities.

In summary, the results of this experiment clearly exclude any model of voicing perception based entirely on VOT analyzers. The most likely site of adaptation is either at the level of VTD detection or at an integrative level which receives inputs from various property detectors. If an integrative level is involved, it does not appear to be located at or beyond the processing stage where phonetic decisions are made.

\section{REFERENCE NOTES}

1. Summerfield, A. Q., \& Haggard, M. P. Perception of stopvoicing. A rate-specific transition detector? Speech Perception, 1972, 2.1, 1-14. (Progress Report of the Department of Psychology, Queen's University of Belfast.)

2. Lisker, L., Liberman, A. M., Erickson, D., \& Dechovitz, D. On pushing the voice-onset-time boundary about. Paper presented at the 89th Meeting of the Acoustical Society of America, Austin, Texas, April 1975. Reprinted in Haskins Laboratories: Status Report on Speech Research, 1975, SR-42/43, 257-264.

3. Blumstein, S. E., \& Stevens, K. N. Property detectors for bursts and transitions in speech perception. Paper presented at the 89 th Meeting of the Acoustical Society of America. Austin, Texas. April 1975.

4. Diehl, R. L., \& Groves, K. A. Phonetic levels of processing in speech perception: Evidence from selective adaptation experiments. Forthcoming.

5. Ades, A. E. Adapting the property detectors for speech perception. Forthcoming.

6. Summerfield, A. Q. Toward a detailed model for the perception of voicing contrasts. Speech Perception, 1974, 2.4, 99-129. (Progress Report of the Department of Psychology, Queen's University of Belfast.)

\section{REFERENCES}

Abramson, A. S., \& Lisker, L. Discriminability along the voicing continuum: Cross-language tests. In Proceedings of the Sixth International Congress of Phonetic Sciences, Prague, 1967. Prague: Academia, 1970. Pp. 569-573.

Abramson, A. S., \& LISKER, L. Voice-timing perception in Spanish word-initial stops. Journal of Phonetics, 1973, 1, 1-8. COOPER, W. E. Selective adaptation for acoustic cues of voicing in initial stops. Journal of Phonetics, 1974, 2, 303-314. 
DIEHL, R. L. The effect of selective adaptation on the identification of speech sounds. Perception \& Psychophysics, 1975, 17, 48-52.

Eimas, P. D., Cooper, W. E., \& Corbit, J. D. Some properties of linguistic feature detectors. Perception \& Psychophysics, 1973, 13, 247-252.

Eimas, P. D., \& Corbit, J. D. Selective adaptation of linguistic feature detectors. Cognitive Psychology, 1973, 4, 99-109.

Lehiste, 1., \& Peterson, G. E. Transitions, glides, and diphthongs. Journal of the Acoustical Society of A merica, 1961, 33, 268-277.

Lisker, L., \& Abramson, A. S. A cross-language study of voicing in initial stops: Acoustical measurements. Word, 1964, 20 , 384-422.

Lisker, L., \& Abramson, A. S. The voicing dimension: Some experiments in comparative phonetics. In Proceedings of the Sixth International Congress of Phonetic Sciences, Prague, 1967. Prague: Academia, 1970. Pp. 563-567.

Stevens, K. N., \& KLATT, D. H. The role of formant transitions in the voiced-voiceless distinction for stops. Journal of the Acoustical Society of America, 1974, 55, 653-659.

Summerfield, A. Q., \& Haggard, M. P. Perceptual processing of multiple cues and contexts: Effects of following vowel upon stop consonant voicing. Journal of Phonetics, 1974, 2, 279-295.

\section{NOTES}

1. We thank James J. Jenkins, who provided us with a tape of these stimuli, which were originally produced at Haskins Laboratories.

2. In all cases, statistical significance was determined by twotailed $t$ tests for correlated observations.

3. As Cooper (1974) has pointed out, two general versions of an integrative acoustic analyzer can be distinguished: an ORgate which responds disjunctively to inputs from separate cuespecific detectors, and an AND-gate which responds to combinations of such inputs. In the latter case, the inputs could determine the response in either an additive or an interactive manner.

(Received for publication December 6, 1976; revision accepted March 14, 1977.) 